\title{
Incidence of large oesophageal varices in patients with cirrhosis: application to prophylaxis of first bleeding
}

\author{
P Calès, H Desmorat, J P Vinel, J P Caucanas, A Ravaud, P Gerin, P Brouet, J P Pascal
}

\begin{abstract}
Because several studies have suggested that $\beta$ blockers are effective in the prophylaxis of first variceal bleeding in cirrhosis, screening for oesophageal varices might be appropriate. We prospectively studied 84 cirrhotic patients without obvious evidence of large oesophageal varices and previous bleeding during a mean follow up of 16 months. At entry to the study 41 patients had no oesophageal varices and in 43 these were grade 1 . The subsequent percentages of patients without large oesophageal varices were $74 \%$ at one year and $52 \%$ at two years. Univariate analysis showed that a longer duration of cirrhosis $(p<0.05)$ and grade 1 oesophageal varices at entry $(p<0.001)$ were predictive factors for the occurrence of large oesophageal varices, whereas, multivariate analysis showed that the initial size of the oesophageal varices $(\mathbf{p}<0.001)$, a high initial Child-Pugh score, and a smaller improvement in Child-Pugh score during the study were independent risk factors. Among patients with grades 0 and 1 oesophageal varices at the start of the study the proportions with large oesophageal varices at two years were $31 \%$ and $70 \%$ respectively. We have calculated that, accepting a maximum risk of first bleeding of $10 \%$ without prophylactic treatment, a patient without oesophageal varices should be screened endoscopically every other year, while a patient with grade 1 disease should benefit from one annual upper gastrointestinal endoscopy.
\end{abstract}

Service d'HépatoGastroentérologie, Centre Hospitalier Universitaire Purpan, Toulouse, France $P$ Calès

H Desmorat

J P Vinel

J P Caucanas

A Ravaud

P Gerin

P Brouet

J P Pascal

Correspondence to:

Dr P Calès, Service d'HépatoGastroentérologie, $\mathrm{CHU}$ Purpan, 31059 Toulouse Cedex, France.

Accepted for publication 22 January 1990

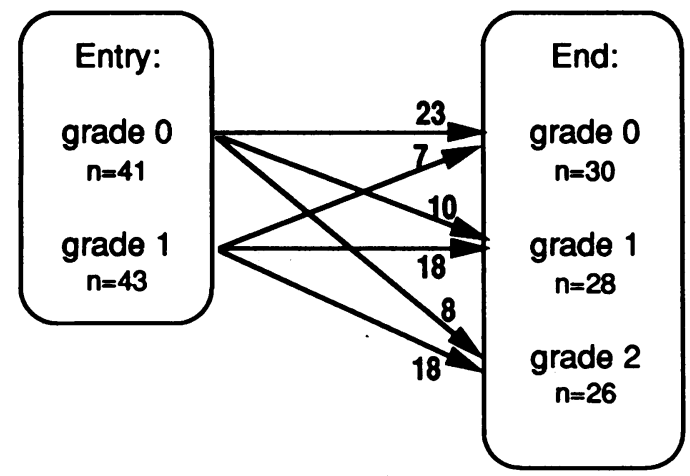

Figure 1: Number of patients according to the variation in variceal size during the course of the study.

Recent studies suggest that $\beta$ blockers provide effective prophylaxis of first upper gastrointestinal tract haemorrhage in cirrhotic patients with large oesophageal varices. ${ }^{1-5}$ In addition, it has been shown that the variceal size or the presence of red signs are independent predictive factors for first bleeding, ${ }^{67}$ and that the first episode of bleeding usually occurs within one year of a diagnosis of oesophageal varices. ${ }^{78}$ In order to recruit cirrhotic patients for primary prophylaxis, therefore, it is important to know the rate of the development of oesophageal varices and the factors associated with this disorder in these patients. Since the natural history of oesophageal varices is poorly documented, ${ }^{8}$ we conducted a prospective study that aimed to determine the rate of development and the factors associated with large oesophageal varices in cirrhotic patients with no history of digestive bleeding.

\section{Methods}

PATIENTS

Adult patients were recruited if they met the following criteria: age below 75 years, cirrhosis confirmed by liver biopsy specimen or suggested by biochemical and clinical data, a Child-Pugh score under 14 , and no large oesophageal varices seen at endoscopy (variceal size < grade 2, see below). The following exclusion criteria were used: a past history of upper gastrointestinal bleeding, hepatic carcinoma, treatment known to alter portal haemodynamics, contraindication to the use of $\beta$ blockers. Patients who had had oesophageal varices diagnosed for more than six months were also excluded.

STUDY PROTOCOL

Every suitable patient who met the above criteria was included in the study. At entry and at each visit, the following data were recorded: alcohol consumption, the presence $(n>5)$ or absence of spider naevi, splenomegaly and hepatomegaly, the Child's criteria as modified by Pugh, ${ }^{9}$ and plasma concentrations of aspartate aminotransferase and alanine aminotransferase. Alcohol consumption habits were evaluated by a dietitian after a detailed interview with the patient. Where there was any doubt, this assessment was based on 
family interview. In addition, to evaluate alcohol abstinence during the study, any decrease in gamma glutamyl transferase and blood alcohol values were taken into account. These parameters were divided into two categories: initial alcohol consumption, estimated as the mean daily amount of ethanol ingested in the months before inclusion, and alcohol withdrawal during the follow up. Patients were asked whether they had signs of intestinal bleeding or if they took vasoactive drugs.

Patients then underwent upper digestive endoscopy and oesophageal varices were graded as follows:

Grade $0=$ no oesophageal varices;

Grade $1=$ oesophageal varices flattened by insufflation;

Grade 2=oesophageal varices that were not flattened by insufflation and were separated by areas of normal mucosa;

Grade $3=$ confluent oesophageal varices that were not flattened by insufflation.

This classification system is similar to those that classify varices as small, medium, and large, and its predictive value for bleeding risk was shown in a prospective study.$^{6}$ The presence or absence of the following endoscopic signs were also considered important in the evaluation: red signs overlying oesophageal varices according to Beppu et $a l,{ }^{10}$ congestive gastropathy according to McCormack et al, " mosaic pattern according to Papazian et $a l,{ }^{12}$ and fundic varices. Other data recorded at entry into the study were age, sex, the cause of the cirrhosis, and the observed duration of cirrhosis. The percentages of variation in Child-Pugh score and alcohol consumption during the course of the study were calculated.

Follow up visits were arranged every 12 months if patients had no oesophageal varices or every six months if they had grade 1 disease. The occurrence of grade 2 or grade 3 disease, variceal bleeding, and death served as end points. In this study, large oesophageal varices are grade 2 or 3 varices. The occurrence of large oesophageal varices was an end point since, as soon as they were detected, propranolol was prescribed. ${ }^{1}$ The sample size could not be calculated owing to insufficient data in the published reports. ${ }^{8}$ It was arbitrarily decided to include at least 100 patients. The censoring date corresponded to the first day when all included patients had had at least two visits (that is, the date of the second endoscopy).

\section{STATISTICAL ANALYSIS}

The $\chi^{2}$ test with Yates's correction, or IrwinFisher-Yates test for small expected numbers were used when appropriate for comparisons between qualitative variables. Student's $t$ test was used for comparisons between quantitative variables, expressed as mean (SD). The occurrence of oesophageal varices was described by Kaplan-Meier plots. ${ }^{13}$ Factors associated with the occurrence of large oesophageal varices were evaluated by univariate analysis according to the log rank test for qualitative variables ${ }^{14}$ and according to the likelihood ratio test for quantitative variables. ${ }^{15}$ Factors which had a p value $<0 \cdot 1$ in univariate analysis as well as the Child-Pugh score, a widely used prognostic indicator, were included in a multivariate analysis according to a logistic regression model. ${ }^{16}$

\section{Results}

\section{POPULATION}

One hundred and one patients were considered for possible inclusion in the study. Two died from causes other than bleeding before the second endoscopy. A further 15 patients were excluded - eight refused the second endoscopy, six were lost to follow up before the second endoscopy, and one violated the exclusion criteria. The following results, therefore, are from the 84 patients in whom at least two visits were recorded. Their mean (SD) age was 54 (11) years, $60 \%$ were men, and $81 \%$ were alcoholic. The distribution according to Child-Pugh grade was: A: $51 \%$, B: $14 \%$, and C: $36 \%$. Forty one patients $(49 \%)$ had no oesophageal varices and 43 (51\%) had grade 1 varices. Cirrhosis was proved by biopsy specimen in $73 \%$ of patients. The median observed duration of cirrhosis was 6 months (range: 0-190 months).

\section{FOLLOW UP DATA}

Nine patients were lost to follow up after the second visit. The mean (SD) follow up was: $15 \cdot 8$ (9.9) months (median: 12, range: 6-42 months). The compliance rate for scheduled visits was $87 \%$. One patient bled from fundic varices 15 days before the next visit; he had grade 2 oesophageal varices at the time of endoscopy. Eight patients died from causes unrelated to upper gastrointestinal tract bleeding. In alcoholic patients, the proportion of total abstinence increased from $18 \%$ to $51 \%(p<0.001)$.

Variceal size remained stable in $49 \%$, increased in $43 \%$, and decreased in $8 \%$ of patients (Fig 1). Grade 2 oesophageal varices occurred in 26 patients, but no grade 3 varices were observed. There was no significant difference between the mean (SD) follow up of patients in whom variceal size increased and that of others (15 (9) $v 16$ (10) months, respectively). The percentage of patients free of large oeso-

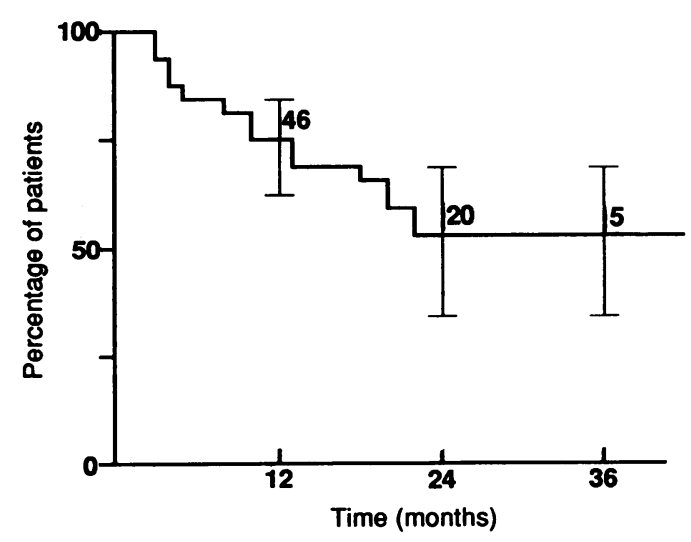

Figure 2: Percentage of patients free of large oesophageal varices in relation to time. Vertical bars indicate $95 \%$ confidence intervals. Numbers are the numbers of patients at risk. 
TABLE I Univariate analysis of factors associated with the occurrence of large oesophageal varices

\begin{tabular}{lcc}
\hline Variable $^{\star}$ & \multicolumn{1}{c}{$\chi^{2}$} & \multicolumn{1}{c}{$p$} \\
\hline Age & $0 \cdot 396$ & NS \\
Sex & $0 \cdot 821$ & NS \\
Cause of cirrhosis & $0 \cdot 280$ & NS \\
Duration of cirrhosis & $4 \cdot 808$ & $<0.05$ \\
Alcohol withdrawal & $0 \cdot 248$ & NS \\
Initial alcohol consumption & 0.013 & NS \\
Variation in alcohol consumption & 0.693 & NS \\
Spider naevi & 0.012 & NS \\
Splenomegaly & 12.024 & $\dagger$ \\
Hepatomegaly & $0 \cdot 174$ & NS \\
Ascites & $0 \cdot 185$ & NS \\
Encephalopathy & 1.955 & NS \\
Initial size of varices & 13.403 & $<0 \cdot 001$ \\
Mosaic pattern & 0.924 & NS \\
Gastropathy & 0.590 & NS \\
Albumin & 0.640 & NS \\
Bilirubin & 0.312 & NS \\
Prothrombin time & 3.503 & NS \\
Aspartate aminotransferase & 0.022 & NS \\
Alanine aminotransferase & 0.011 & NS \\
Initial Child-Pugh score & 1.399 & NS \\
Variation in Child-Pugh score & 1.740 & NS \\
\hline
\end{tabular}

^Evaluated according to $\log$ rank test and likelihood ratio test, respective qualitative and quantitative variables.

tExpected numbers were too small.

phageal varices was $74 \%$ (95\% confidence intervals: $62-83 \%)$ at one year and $52 \%$ at two years (95\% confidence intervals: $38-66 \%$ ) (Fig 2). The rate of occurrence of large oesophageal varices seemed to be linear during the first two years.

During the follow up period, the proportion of patients with mosaic pattern, gastropathy, or fundic varices significantly increased, whereas the small prevalence of red signs overlying oesophageal varices did not permit calculation. Among the above endoscopic signs, only mosaic pattern followed a development roughly parallel to that of variceal size. Indeed, mosaic pattern occurred in $36 \%$ of patients whose variceal size increased $v 15 \%$ in other patients $(\mathrm{p}<0.05)$. For the occurrence of gastropathy, red signs, and fundic varices, the differences were not significant.

FACTORS ASSOCIATED WITH THE OCCURRENCE OF LARGE OESOPHAGEAL VARICES

Using univariate analysis, the factors significantly associated with the occurrence of large oesophageal varices (Table I) were a longer duration of cirrhosis and the presence of grade 1

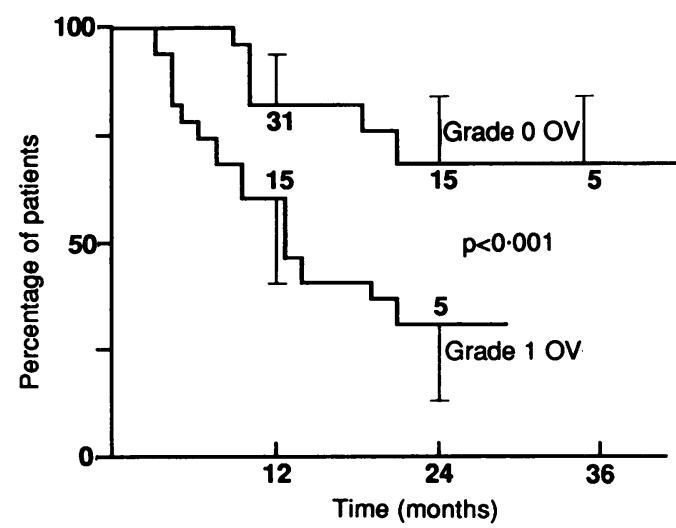

Figure 3: Percentage of patients free of large oesophageal varices $(\mathrm{OV})$ in relation to time according to the initial size of oesophageal varices. Vertical bars indicate $95 \%$ confidence intervals. Numbers are the numbers of patients at risk.
TABLE II Multivariate analysis of factors associated with the occurrence of large oesophageal varices

\begin{tabular}{lll}
\hline Variable & $\chi^{2}$ & $p$ \\
\hline Initial size of varices & 10.904 & $<0.001$ \\
Variation in Child-Pugh score & 7.312 & $<0.01$ \\
Initial Child-Pugh score & 5.572 & $<0.05$ \\
Duration of cirrhosis & 1.233 & $\mathrm{NS}$ \\
Splenomegaly & 1.049 & $\mathrm{NS}$ \\
\hline The relative importance of the variable is given by the numerical \\
value of $\chi^{2}$. Details on the first three variables are depicted in \\
Figures 3 and 4.
\end{tabular}

varices at entry into the study. The percentages of patients free of large oesophageal varices were 85 and $61 \%$ at one year and 69 and $30 \%$ at two years, in patients with initial grade 0 and grade 1 oesophageal varices respectively (Fig 3).

Using multivariate analysis, grade 1 oesophageal varices at entry, a higher initial ChildPugh score, and a smaller decrease in the Child-Pugh score during follow up were shown to be independent factors for the development of large oesophageal varices (Table II). In this model, the overall significance had a $\mathrm{p}$ value $<0.001 \quad\left(\chi^{2}=28.194\right)$ and the value of $r^{2}$ was $0 \cdot 102 .{ }^{16}$ The assumption of proportional hazard was checked by goodness of fit testing: $\chi^{2}=5 \cdot 212$ with $5 \mathrm{df}$, NS. ${ }^{17}$

Thus, the predictive value of the Child-Pugh score was seen only in multivariate analysis. Figure 4 shows that the initial Child-Pugh score was not significantly different in the group of 36 patients in whom variceal size increased during the study than in the group of 48 in whom it did not. By contrast, the Child-Pugh score decreased significantly during the study only in the latter group so that the Child-Pugh score was significantly greater in patients with increased variceal size at the end of the study.

THE OCCURRENCE OF OESOPHAGEAL VARICES We studied the development of oesophageal varices in the 41 patients who did not have these at entry to the study. Oesophageal varices occurred in 18 patients (Fig 1). The percentage of patients free of varices was $77 \%$ at one year $(95 \%$ confidence intervals: 61 and $88 \%$ ) and $50 \%$ at

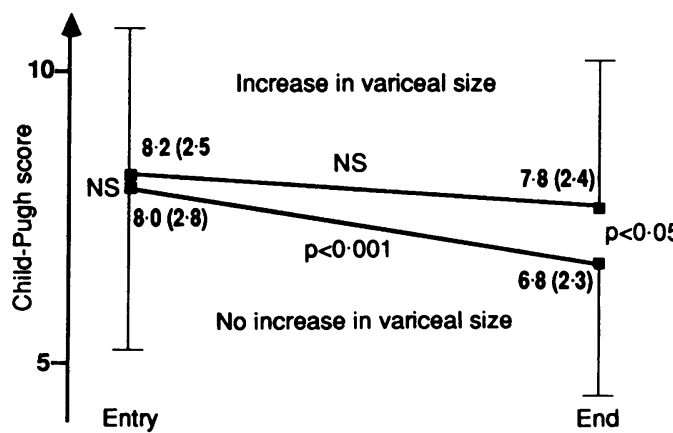

Figure 4: Comparison of the mean Child-Pugh score in the groups of patients with (top) and without (bottom) an increase in oesophageal variceal size and within each group at the beginning and at the end of the study. Comparisons were not performed between the group of patients in whom large oesophageal varices occurred and other patients since their mean (SD) follow up was significantly different (12 (6) v 17

(11) months, respectively, $p<0.05)$. In the whole population the mean $(S D)$ Child-Pugh score decreased significantly from $8 \cdot 1(2 \cdot 7)$ to $7 \cdot 2(2 \cdot 4)(p<0 \cdot 001)$. 
two years (95\% confidence intervals, 34 and $68 \%)$. Using univariate analysis, no variable was significantly associated with the occurrence of oesophageal varices, while using multivariate analysis, the variation in Child-Pugh score had a $\mathrm{p}$ value $<0 \cdot 1$. Indeed, the Child-Pugh score significantly decreased only in patients without oesophageal varices throughout the study $(p<0.05)$ so that its score became significantly different between patients with and without oesophageal varices at the end of the study $(\mathrm{p}<0.05)$.

\section{Discussion}

The natural history of oesophageal varices needs to be studied as soon as cirrhosis occurs, otherwise selection biases will be introduced inevitably. Such a study, however, is far beyond the possibilities of a clinical approach. In this study, we decided to rule out the major bias by excluding patients in whom oesophageal varices were known to be present for more than six months. Indeed, they represented a selected subgroup in whom no bleeding had occurred. Patients who presented initially with large oesophageal varices were not considered for the study and those in whom large oesophageal varices had occurred were excluded since they were being given propranolol for primary prophylaxis of bleeding.

Our results show that in a group of cirrhotic patients with grade 0 or grade 1 oesophageal varices, $31 \%$ developed large varices after a mean follow up of 16 months. Dagradi observed that variceal size increased faster in the first year after their discovery than later on. ${ }^{18}$ We observed a decrease in variceal size in $8 \%$ of our patients during the period of the study. Our results cannot be compared with other works where the size of varices was found to decrease in up to $30 \%$ of the patients ${ }^{819}$ since our results deal only with grade 1 varices. Our results did not seem to be biased by the high rate of alcohol withdrawal, since this factor was not predictive for the occurrence of large oesophageal varices. A high rate of occurrence of large oesophageal varices over a short time could explain why variceal size was not found to be a prognostic factor for survival in several studies. ${ }^{620}$

The natural history of oesophageal varices has been described by Dagradi. ${ }^{18}$ He stated that the average time observed for the transition from the least to the most highly developed stage of the varices was approximately 50 months. However, this was in a selected group of men with cirrhosis whose alcohol consumption was sustained. Czaja et al calculated that the likelihood of developing varices after a diagnosis of cirrhosis was $8 \%$ after one year and $13 \%$ after five years, but these patients had severe chronic active liver disease treated with prednisone and oesophageal varices were diagnosed by $x$ ray in most. ${ }^{21}$ Christensen et al showed that the cumulative percentage of patients in whom oesophageal varices had been shown by radiography but who had not experienced bleeding increased from 8 to $83 \%$ over 10 years. ${ }^{22}$ Nevertheless, the actual percentage of patients with oesophageal varices might have been less, since this calculation did not take into account the proportion of patients in whom variceal size regressed. The Mayo Clinic group showed that oesophageal varices occurred in $31 \%$ of patients with primary biliary cirrhosis followed for a median of six years. ${ }^{23}$

It is not surprising that the initial size of oesophageal varices was the best predictive factor of occurrence of large varices owing to the well known propensity of oesophageal varices to grow. ${ }^{8} \mathrm{~A}$ longer duration of cirrhosis in patients with large oesophageal varices has already been suggested. ${ }^{19}$ The initial Child-Pugh score had no predictive value for the occurrence of large oesophageal varices. Indeed, the predictive value of the Child-Pugh score was shown only where multivariate analysis was used. A slightly different course in the Child-Pugh score between patients in whom oesophageal variceal size increased and those in whom it did not was observed (Fig 4). Finally, the parallelism between the course of the Child-Pugh score and variceal development suggests a relation between these two factors. This result in a longitudinal study was also expected since we have previously observed that the Child-Pugh score correlated with the size of oesophageal varices in a cross study of cirrhotic patients. ${ }^{24}$ The same predictive value of hepatic dysfunction was shown for the occurrence of oesophageal varices in primary biliary cirrhosis by Cox analysis ${ }^{23}$ but this tendency was not noted in other types of cirrhoses by Palmer. ${ }^{19}$ Alcohol consumption habits had no predictive value for the development of oesophageal varices in our series; this result contrasts with the observation made by Dagradi. ${ }^{18}$ No oesophageal variceal bleeding occurred in this group of patients. This finding agrees with previously published data that showed that:

(a) In cirrhotic patients whose variceal size was
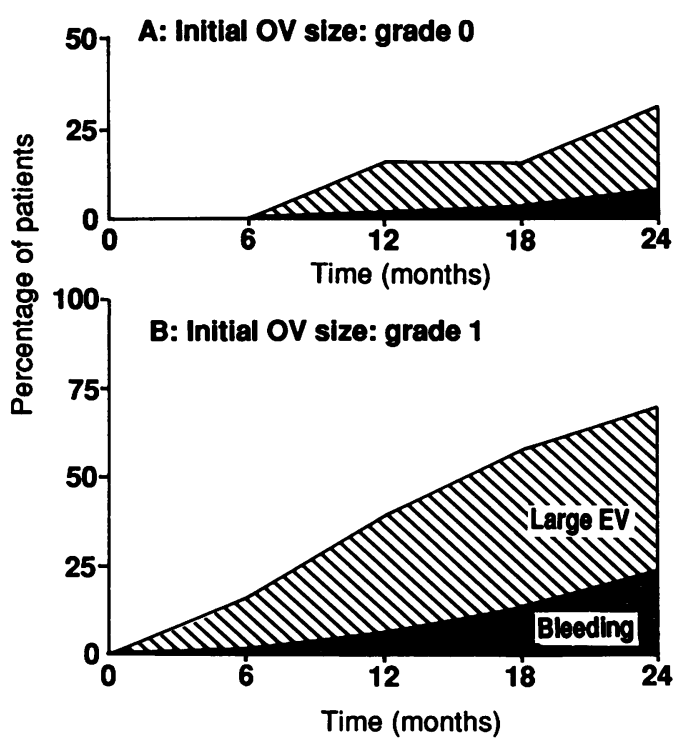

Figure 5: Cumulative percentages of patients with large oesophageal varices $(O V)$ and estimated risk of bleeding, during a 24 month follow up in two groups of patients, A: patients with grade 0 OV at entry (top), B: patients with grade $1 \mathrm{OV}$ at entry (bottom).

The percentages of patients with newly diagnosed grade 2 $O V$ (hatched area) are derived from Figure 3. The probability of bleeding (black area) is derived from the data of placebo group patients with grade $2 \mathrm{OV}$ observed in our prophylactic trial ie, 12, 22, 39, and 59\%, respectively at $6,12,18$, and 24 months after the diagnosis of $O V .^{\prime}$ These cumulative percentages were calculated at intervals of six months. 
repeatedly evaluated, variceal bleeding occurred only in those with the largest varice ${ }^{18}$;

(b) The occurrence rate of oesophageal varices is higher than that for bleeding from varices, showing that it may take some time before the varices reach a size that makes them likely to bleed. ${ }^{22}$

Approximately one of three cirrhotic patients will experience variceal bleeding, and one of them will die from the first episode. ${ }^{8}$ As the first bleeding occurs early in the development of cirrhosis or oesophageal varices, it is important to determine when to perform endoscopic screening aimed to detect large oesophageal varices so that primary prophylaxis can be given. The rate of occurrence of grade 2 oesophageal varices according to the initial size of varices is shown in Figure 5. We extrapolated the bleeding risk for these large varices from the incidence of first bleeding observed in the placebo patients with grade 2 varices in our study of prophylaxis of bleeding. ' Thus, we can observe from these figures that the bleeding risk is less than $8 \%$ at two years in patients with initial grade 0 varices and less than 6 and $24 \%$ at one and two years respectively in patients with initial grade 1 varices. Aiming at primary prophylaxis and accepting a maximum risk of $10 \%$ of first bleeding without prophylactic treatment, we propose that an upper gastrointestinal endoscopy should be performed every other year in patients with no oesophageal varices and every year in patients with grade 1 varices. This estimation should be viewed with caution, however, since:

(a) The calculation of the bleeding rate is an overestimate because of the unknown time lag between the approximate date of occurrence of grade 2 oesophageal varices (present study) and the date of diagnosis of these varices (prophylactic trial);

(b) This schedule has to be validated in longterm studies;

(c) This schedule could be simplified: if we consider that three quarters of patients with grade 1 oesophageal varices will have grade 2 varices two years later, prophylaxis could be started from the diagnosis of grade 1 varices.

1 Pascal JP, Calès P, and a Multicenter Study Group. Propranolol in the prevention of first upper gastrointestinal tract pranolol in the prevention of first upper gastrointestial tract esophageal varices. N Engl F Med 1987; 317: 856-61.
2 Ideo G, Bellati G, Fesce E, et al. Nadolol can prevent the first gastrointestinal bleeding in cirrhotics: a prospective, randomized study. Hepatology 1988; 8: 6-9.

3 The Italian Multicenter Project for Propranolol in Prevention of Bleeding. Propranolol prevents first gastrointestinal bleeding in non-ascitic cirrhotic patients. Final report of bleeding in non-ascitic cirrhotic patients. Final report

4 Lebrec D, Poynard T, Capron JP, et al. Nadolol for prophy laxis of gastrointestinal bleeding in patients with cirrhosis: $A$ randomized trial. F Hepatol 1988; 7: 118-25.

5 Bosch J, Groszmann RJ, Grace N, et al. Propranolol in the prevention of the first hemorrhage from esophageal varices: results of a randomized, double-blind, cooperative clinical trial [Abstract]. F Hepatol 1988; 7: $\$ 12$

6 Calès $\mathrm{P}$, et Groupe d'Etude de la Prophylaxie Primaire. Facteurs prédictifs de la première hémorragie digestive et de la mortalité chez les malades cirrhotiques avec varices oesophagiennes. Gastroenterol Clin Biol 1989; 13:54-9.

7 The North Italian Endoscopic Club for the Study and Treat ment of Esophageal Varices. Prediction of the first variceal hemorrhage in patients with cirrhosis of the liver and hemorrhage in patients with cirrhosis of the liver
esophageal varices. N Engl f Med 1988; 319: 983-9.

8 Calès P, Pascal JP. Histoire naturelle des varices oesophagiennes au cours de la cirrhose (de la naissance à la rupture) Gastroenterol Clin Biol 1988; 12: 245-54.

9 Pugh RNH, Murray-Lyon IM, Dawson JL, et al. Transection of the oesophagus for bleeding oesophageal varices. $\mathrm{Br} \mathcal{F}$ Surg 1973; 60: 646-9.

10 Beppu $\mathrm{K}$, Inokuchi $\mathrm{K}$, Koyanagi $\mathrm{N}$, et al. Prediction of variceal hemorrhage by esophageal endoscopy. Gastrointest Endosc 1981; 27: 213-8.

11 McCormack, TT, Sims J, Eyre-Brook I, et al. Gastric lesion in portal hypertension: inflammatory gastritis or congestive in portal hypertension: inflammatory

12 Papazian A, Braillon A, Dupas JL, et al. Portal hypertensive gastric mucosa: an endoscopic study. Gut 1986; 27: 1199 203.

13 Kaplan EL, Meier P. Nonparametric estimation from incom plete observations. F Am Stat Assoc 1958; 53: 457-81.

14 Peto R, Pike MC, Armitage P, et al. Design and analysis of randomized clinical trials requiring prolonged observation of each patient. II. Analysis and examples. Brf Cancer 1977 35: 1-39.

15 Poynard T, Chaput JC, Mary JY, et al. Analyse critique des facteurs liés à la mortalité au trentième jour dans les hémorragies digestives hautes du cirrhotique. Gastroenterol Clin Biol 1980; 4: 655-65.

16 Christensen E. Multivariate survival analysis using Cox's regression model. Hepatology 1987; 7: 1346-58.

17 O'Quigley J, Moreau T. Testing the proportional hazards regression model against some general alternatives. $R e$ Epidemio et Santé Publ 1984; 32: 185-98.

18 Dagradi AE. The natural history of esophageal varices in patients with alcoholic liver cirrhosis. An endoscopic and clinical study. Am $\mathcal{F}$ Gastroenterol 1972; 57: 520-40.

19 Palmer ED. On the natural history of esophageal varices which are secondary to portal cirrhosis. Ann Intern Med 1957; 47: $18-26$.

20 Poupon RE, Thibult N, Barbare JC, et al. La taille des varices oesophagiennes a-t-elle une signification pronostique au cours des cirrhoses alcooliques? Gastroenterol Clin Biol 1987, 11: $119-22$.

21 Czaja AJ, Wolf AM, Summerskill WHJ. Development and early prognosis of esophageal varices in severe chronic active liver disease (CALD) treated with prednisone. Gastroenterology 1979; 77: 629-33.

22 Christensen E, Faverholdt L, Schlichting P, et al. Aspects of the natural history of gastrointestinal bleeding in cirrhosi and the effect of prednisone. Gastroenterology 1981; 81: 944 52.

23 Gores GJ, Wiesner RH, Dikson ER, et al. Prospective evaluation of esophageal varices in primary biliary cirrhosis: development, natural history and influence on survival. Gastroenterology 1989; 96: 1552-9.

24 Cales P, Zabotto B, Meskens C, et al. Gastro-esophagea endoscopic features in cirrhosis: observer variability, interassociation, and relation to hepatic dysfunction. Gastroenterology 1990; 98: 156-62. 